\title{
On a solution to the "cheaters" and "consultants" problem within online educational service
}

\author{
Anton Anatolievich FINOGENOV ${ }^{1 *}$, Natalia Sergeevna GILMANOVA ${ }^{2}$, Svetlana Valentinovna VLADIMIROVA ${ }^{3}$ \\ ${ }^{1}$ Yugra State University, Digital Economy Institute, Associate Professor, \\ ${ }^{2}$ Yugra State University, Institute of Human Science and Northern Studies, Associate Professor, \\ ${ }^{3}$ Yugra State University, Institute of Human Science and Northern Studies, Associate Professor
}

\begin{abstract}
One of the obvious drawbacks of online education service is the inability to control the students in solving tasks themselves. This leads to mass cheats and, as a result, to the devaluation of issued certificates. The article offers some technical tool which can partially reduce the damage from this phenomenon in online education. The originality of the proposed technical tool lies in the interaction of two well-known educational procedures: 1) peer cross-reviews and 2) creating a portfolio. The article discusses the details of this proposal for possible implementation.
\end{abstract}

Keywords: Online Education, Knowledge Assessment, Remote Education.

\section{INTRODUCTION}

Problem description: Ideally, there are three actors in an online education system: Lecturers, Students, and Employers. The process of providing educational services online is as follows:

1. Lecturers distribute tasks to Students.

2. The Students send the solutions back to the Lecturers.

3. The Lecturers check the solutions.

This cycle reproduces several times, and as a result, the Lecturers pass the Students (graduates) to the Employers along with certain certificates, the meaning of which is: "This Student is capable of independent working activities."

Giving lectures, distributing textbooks, answering questions, and other teaching activities related to learning, rather than "providing an online educational service" in the above sense, are not covered in this article.

In the realm of online education, there are two other wellknown actors. In this article, we will call them "Cheaters" and "Consultants":

1. Cheaters pretend to be "Students", get the tasks, and pass them on to Consultants.

2. Consultants solve the tasks and pass the decision back to the Cheaters.

3. The Cheaters pass the products of the Consultants back to the Lecturers.

Thus, some of the Lecturers' efforts are spent on pointless filtering of the Consultants' products and on the surreal conversations with the Cheaters.

In case the number of the Cheaters and Consultants enormously grows, providing educational services distorts to the point of complete nonsense:

1. Most of the Lecturers' efforts are spent on meaningless activities, and after a while, they simply stop checking and filtering anything, adopting the principle "as they saw, so shall they reap".

2. The Certificate given to the Employer along with the Student (or the Cheater) ceases to mean anything, and Employers must deal with filtering and conversations themselves.

As an illustration of the complete absurdness of the situation, it serves the famous story about drawing a diode bridge [1], and the phrase that was found on one of the Consultants' resources "...your order will be completed as soon as possible. Most of the time is spent on paying for the order. Also for this reason, the cost of examples from these task books is minimal (from 8 rubles per example / task). For other task books, the prices are slightly higher (from 20 rubles per example / task)...". One can easily assess the scale of the problem by "googling" the phrase "help in online learning".

Traditional methods of combating this phenomenon, which involve calls for ethics and increased control [2,3], are useless with teaching online. The attempt to make the problem invisible with the help of "objective tests" with "the answer is a number" leads to even faster degradation of education, because it makes it impossible to set meaningful tasks and pointlessly complicates the life of those few students who are sincerely trying to learn something. Proctoring and other modern and expensive surveillance tools will certainly enrich proctors, anti-proctors, and micro-ear manufacturers, but will make the lives of normal students completely unbearable, and surreal conversations with cheaters will become even more surreal.

\section{METHODOLOGY}

Three ideas are proposed as a solution to the problems caused by the intermediating of Cheaters and Consultants in online education systems:

1. Partially shifting the work verification on to the Consultants (and Students) themselves. 
2. Using the Students' (and Cheaters') works as the Certificates.

3. Anonymity.

\section{Idea 1}

The idea of checking the work by students themselves is not new, and has been studied in sufficient detail $[4,5,6]$.

Mutual verification is already implemented in some online systems, and looks like this:

1. A Student (or a Cheater) receives a task, solves it with a pen on paper, takes a photo, and sends it to the Lecturer (more precisely, to a learning system).

2. The solution (i.e. a photo of the solution) along with the correct answer or verification instructions is sent to several random students (or cheaters).

3. These random students (or consultants related to cheaters) check the correctness of the solution and assess it with a mark (give it a score).

4. In this way, the Student's (or Cheater's) work gets several ratings that were given by several random students (or consultants), and these ratings are constituting the assessment when issuing the certificate.

It is proposed to bring this system of mutual verification to its logical end:

1. Assessment rating is introduced, students (and cheaters) earn and spend scores.

2. To get a ready work assessed costs a score (or any other number of scores agreed on).

3. For a correct verification and rating of someone else's work, the Student (or the Cheater) is paid some remuneration (less than one score).

4. Finally, the correctness or wrongness of the work, and, accordingly, the correctness or wrongness of the checks of this work is determined by the Lecturer.

5. Thus, what students do should be called a peer review / pre-assessment.

6. The Lecturer does not start checking immediately after having received the work, but only after the results of pre-assessment by the students (or the consultants) appear.

7. The Lecturer thus can be directed by the results of these pre-assessments, for example, leaving the obvious cheaters behind on "self-service" and focusing on the real students.

8. To advance in a course, the Student must have a positive balance counted in scores, i.e. for the opportunity to submit one of their work to the preassessment, the Student will have to "earn it" by checking several others ' works.

It is important to note that pre-assessment scores are not related to the assessment of academic performance, they are more in line with the concept of "pay for work", i.e. pay for activities that benefit other people. It should also be noted that there is no need to "check the pre-assessment", since its correctness logically follows from the coincidence of the scores given by the Student and the Lecturer.

\section{Idea 2}

As a certificate, the Employer receives not just a piece of paper with a seal, but a complete set of all tasks with solutions "written in hand" of the Student (or Consultant).

If the Employer is interested, they can filter and interview the Students themselves, but now they no longer need to remember their own student years and come up with questions about the "diode bridge", they now have grounds for asking meaningful questions like:

1. Please tell us what you have written here, because you wrote it yourself, didn't you?

2. Here is the same kind of task, you have already solved it, can you solve it again?

3. What do you mean by "We did not have this at the University"? Here is the same task that had been given to you by the University lecturers and you have already successfully solved it.

If the Employer is not interested, then everything remains the same as before: the Cheater, the Consultant and the Employer will get what they wanted, absolutely honestly.

\section{Idea 3}

Students are present in the system as a "nickname" or an email address. Personal data is unnecessary and even harmful, because:

1. Before sending out works for mutual verification, they will still have to be anonymized.

2. "Portfolio" (in the form of all the works done by the claimer of a job) may not contain any personal data, and it is anyway impossible to find out who exactly completed this work during online training.

3. Anonymity will allow you to avoid prosecution as per the law on the protection of personal data or as per any other law.

4. This system may remain unlinked to any higher education institution or even to any higher-level bureaucratic structures of the education system.

\section{RESULTS}

If this system is successfully implemented:

1. Lecturers will focus on students

2. Students will become "not only writers, but also readers", which is useful in itself [4].

3. Cheaters with Consultants will have to serve themselves and, as a nice bonus, will also help to check the Students' works.

4. Even if the number of Cheaters along with Consultants will significantly exceed the number of the Students, the system will remain functional, since the Students' works will be checked by several highly qualified Consultants, and vice versa, the Students 
will come to check mostly well-designed works written by highly qualified Consultants.

5. Teachers will stop "laundering" Cheaters' works by turning them into certificates signed with their own name.

6. Employers will receive full information about the Student's education and will be able to check its accuracy themselves (in case they wish to do so).

\section{DISCUSSION}

Possible problems and solutions are discussed below.

Problem 1: "Trolling". Anonymous participants can try and sabotage the process by sending unreadable messages as works for assessment, inappropriate images, or by performing deliberately incorrect checks.

To combat this, the system must calculate the "ratings" and take them into account when assigning a fee for pre-verification and pre-assessment:

1. For an incorrectly performed check, the Student's "assessment rating" will be lowered, and for the following checks, his "pay" will be less.

2. Sending "inappropriate images" will be blacklisted and pre-moderated for a separate "fee" with scores.

3. For a poorly designed work, the Student's "design rating" will be lowered, and for checking the following works, they will be charged a large fee (and, accordingly, pay more to those who will check such works).

Thus, antisocial behavior will lead to the need to check more and more of other people's work, and will become unprofitable.

The task of calculating a fair fee for pre-assessment and the task of adequately assessing the results of verification is nothing more than a standard task from applied statistics: Students are "inaccurate devices" that need to "measure the detail" (check the work). It is a well-known type of conclusion which is made on the "value" of certain measuring devices in case their indications are inaccurate.

Fair payment for verification of complex or poorly designed works can be assigned by the "second-price auction" method: Students (or Cheaters) first look at the work, offer a fee for verification, and thus participate in the auction.

And even if there are saboteurs who completely refuse to check anything, they will get their "certificate" but in the form of a pack of unverified works.

Problem 2: "Deadlock". When you start the system and/or at the beginning of a new topic, there will be a lot of people who want to submit the work for pre-assessment, but do not have enough scores. And vice versa, there will be a lot of people who want to earn scores but are not ready to check the work on this topic.

Usually, tasks have some natural hierarchy (for example, the division is studied after multiplication, and multiplication after addition), so undergraduates can check the tasks solved by first years students.
After some time, a Reference Bank of tasks with reference solutions will accumulate, which can be used to determine the test ratings and to "build the initial capital" by the Students.

Problem 3: Ordinary tasks from ordinary task-books will soon become known, along with the solutions, and will become of little use.

As a source of tasks for this system, any task generators are ideal. A lot of them have already been developed [7-17; 27-36]. Work on this topic is also being conducted abroad $[18,19,20]$. There are freely distributed open-source generators [17, 18], and [20] includes a detailed overview. The unpopularity of generators in traditional teaching is ingeniously explained in [8] (p. 7), but they will become especially useful for the proposed system.

Problem 4: Cross-checking does not work in small groups where everyone knows each other. Evaluation of works by inexperienced students is difficult in the case of creative tasks.

The proposed system is not universal. It makes sense in mass education systems and in standardized basic academic disciplines, which have enough grades on the scale between "unambiguously correct" and "unambiguously wrong". The suggested system is not aimed at being applied in every discipline.

Problem 5: Technical difficulties with implementing and maintaining the system in a working state.

The system does not need to be created "from scratch". Many online learning systems already contain a mechanism for students to cross-check their work (for example, in Moodle, this is called a course element "workshop" or Activates Workshop) but, in contrast to the proposed system, they contain odd (in our opinion) elements like "assessment for assessment" and mechanical addition of the assessment set by the teacher with the assessment set by the students.

Making the proposed changes to existing online learning systems should not be difficult.

Also, this training system can be implemented as a bot in one of the messengers, since the messenger takes care of many technical problems, not connected with education, such as registration, mailing, receiving and storing images and files.

The intended interface of the intended system might look like this:

1. A Lecturer in the role of a teacher creates a chain of tasks in several ways (using a task generator or manually) and puts it in the system. These tasks are sent out to Students according to the schedule.

2. A Lecturer in the role of the examiner receives the students' works along with the results of the preassessments, with the counted probability of correct work (calculated by the system based on the ratings of the examiners), with the statistics on every Student and other information. After that, they can

a. approve the rating "without looking" (for example, in the case of obvious cheating) or

b. review the solution, issue the final score, and enter information about the Student in their 
"black notebook".

1. The Student in the role of a student receives the next task, solves it with a pen on a piece of paper (or something else), takes photos (if the work is on paper), and (if there are enough scores on his account) puts the work in for review. Perhaps, in the case of a poorly designed work, there will not be anyone willing to preassess it, and then the Student will either have to agree to a higher price, or put another solution to the same task in for pre-assessment.

2. The Student in the role of pre-assessor receives the work of another Student for review along with the offer of payment and

a. either agrees to the payment, receives a verification prompt from the system, checks the work, and sends a rating (correct/incorrect);

b. or (in the case of a difficult task or poorly designed work) refuses and demands an increase in payment. In this case, a "second price auction" is held, and the work is re-sent for verification at a higher price.

A draft version of the implementation of such a system based on messenger can be a good graduate work of a student programmer.

\section{FINANCING}

This educational service has a natural client who is interested in it: an Employer recruiting specialists able to work in their specialty. In the current reality, these Employers have to independently spend their resources on conducting the exam when recruiting for a job. A "certificate" for a Student (or Cheater) in the form of a set of completed works is valuable information for the Employer, and it would be quite natural if the employers pay for it, thus financing the work of the system.

Perhaps in the nearest future, employers will hear the special opinion of the judge of the constitutional Court of the Russian Federation K. V. Aranovsky [25] and start building their own system of training and evaluating their future employees. And then the proposed ideas will be particularly relevant.

\section{CONCLUSION}

The war between lecturers, professors and cheaters, similar to the competition of armor and projectile, is well known to everyone who has worked with students for a long time. In this war, "armor" protected the reputation of the University and the associated academic rent [26]. At present, in terms of per capita funding, annual work contracts for the professors, and surveys of students on the subject of "satisfaction with the quality of educational services provided", the "armor" has no reason to protect anything. There are hardly any situations abroad, to compare with.

What the article suggests is not "fighting cheating" and neither trying to stop what can not be stopped, but focusing on reducing the damage caused. The training system described above is not revolutionary, it is offered as a computer tool that corresponds to the existing "de facto" situation, in which professors are forced to ignore cheaters, and employers are forced to independently conduct a pseudo-exam.

The components of the proposed system (student peer crossreview and portfolio accumulation) are not new, but they are not particularly effective separately:

1. In the current situation, where students consider themselves "clients receiving a service", writing test papers is perceived by them as something useless, just necessary to "break through the armor of the teachers", and as something that will eventually go to the trash bin.

2. The Portfolio usually involves collecting successes (but not failures) in the form of framed awards and diplomas with a seal, which in the conditions of an abundance of cheaters generates the same "competition of armor and projectile", therefore, is not particularly different from the usual diploma of education and does not represent informative value for employers. Teachers could supposedly collect all the students ' papers and attach them to the diploma, but, of course, no one will actually do this.

3. It is absurd to rely on the integrity of students when checking other people's work in terms of per capita funding. If the professor can somehow justify the "failure" result they put with an incorrectly solved task, then it is impossible to put a "failure" for the fact that the student "performed the teacher's work" poorly. Of course, peer cross-checks make some sense as another educational procedure, but the ratio of educational effect to the efforts of professors to organize and "check checks" is hardly any better than the same ratio for more traditional educational procedures.

The novelty of the proposed system consists in a fundamentally new interaction of the above-described components:

1. Automatic portfolio creation will change the value of test papers for students, since they will turn into something like "initial capital", useful for employment.

2. The need to send papers in for peer cross-review will change the students' attitude to their designing (since they will now be seen by the other "recipients of educational services" equal to themselves in social status) and will make it possible to automatically accumulate a portfolio.

3. In the end, the main purpose of the proposed system is to separate the world of professors with students from the world of "cheaters" with "consultants". Of course, in the world of professors and students, assessing of test papers should be done by professors, no matter what happens in the world of cheaters with consultants. But the boundary between these worlds is difficult to define. It is assumed that a system of peer cross-review with verification forced by scoring points will help avoid the degradation at the border between worlds. 
International Journal of Engineering Research and Technology. ISSN 0974-3154, Volume 13, Number 11 (2020), pp. $3849-3854$

(C) International Research Publication House. https://dx.doi.org/10.37624/IJERT/13.11.2020.3849-3854

\section{REFERENCES}

[1] Chikov, N. V. Engineering culture, which we lost? [Electronic resource]. - Mode of access: https://habr.com/post/233851 (date accessed: 21.1.2019)

[2] Eremenko T. V. Information and ethical situations of plagiarism in the Russian University community: based on the materials of scientific and professional periodicals (2006-2015) / / Internet Journal "NAUKOVEDENIE" Volume $7, \quad$ No 4 (2015) http://naukovedenie.ru/PDF/49PVN415.pdf (access is free). Caption from the screen. Rus., Eng. DOI: 10.15862/49PVN415

[3] Fokina V. N., Sliva A.V., Semenova T. Yu., Abramova A.V. The Problem of academic dishonesty and some ways to solve it in higher education // Innovations in Education. 2012. no. 11. pp. 86-97.

[4] Karpenko M. P., Basov V. A., Semenova T. Yu., Sliva A.V., Fokina V. N. Problems of mutual evaluation in the educational work of students // Sociology of Education. 2014. No. 6. Pp. 4-13.

[5] Arlashkina O. V. Application of the method of peerreview in management training // Bulletin of the Lobachevsky University of Nizhny Novgorod. Series: Social Sciences. 2018. No. 2 (50). Pp. 132-141.

[6] Velikova L. N. Didactic potential of students peer-review in a foreign language class // In the collection: Language aspects of professional communication in the modern educational environment. Collection of materials of the II International scientific and practical conference. Russian Customs Academy. 2017. Pp. 16-20.

[7] Finogenov A. A. Using the task generator for controlling knowledge of higher mathematics in Junior students // Bulletin of Yugra State University No. 2/41, 2016. pp. 6567.

[8] Okishev S. V. the Problem of creating and using generators and solvers of mathematical problems // The Internet Magazine "World of Science", 2018 No. 3, https://mir-nauki.com/PDF/56PDMN318.pdf (access is free). Caption from the screen. Rus., Eng.

[9] Zorin Yu. A., Posov I. A. Instrumental systems for constructing and obtaining multivariate test tasks / / Computer Tools in Education. 2014. No. 1. Pp. 14-25.

[10] Kruchinin V. V., Morozova Yu. V., Zorin Yu. A. Construction and use of test task generators in distance learning systems // Open and Remote education. 2018. No. 3 (71). Pp. 5-11.

[11] Zorin Yu. A. Use of combinatorial generation algorithms in the construction of test task generators / / Remote and Virtual training, 2013, No. 6. Pp. 54-59.

[12] Konovalov Ya. Yu., Sobolev S. K., Ermolaeva M. A. Methodological aspects of automatic generation of linear algebra problems // Engineering Journal: Science and Innovation. 2013. No. 5(17). 14 p. Access mode: http://engjournal.ru/catalog/pedagogika/hidden/740.html (accessed: 06.12. 2019).

[13] Shvetsov A. N., Mamadkulov Yu. O., Sorokin S. I. System of synthesis of educational tests based on formal grammars // Software Products and Systems. 2013. No. 2. P. 181 to 185 .

[14] Lichargin D. V., Usova A. A., Sotnikova V. V., Lipman S. A., Butovchenko V. V. Developing an application for generating training tasks for a text in natural language based on generated templates // Modern Problems of Science and Education. 2015. No. 2 (2). URL: http://www.science-

education.ru/ru/article/view?id=22636 (accessed: 21.01.2019).

[15] Sychev S. V. Automatic generation of test tasks in chemistry with qualitative and quantitative variations. Informatics and Education. 2016. No. 5 (274). Pp. 46-53.

[16] Yudin S. V. Generator of control (calculation and graphic) works in mathematics for first-year University students // Scientific and methodological electronic journal "Concept". 2016. No. 8 (August). P. 9-14. URL: http://e-koncept.ru/2016/16158.htm .

[17] Kurdubov S. L., Kurdubova V. V. Flexible generator of Autonomous tests in discrete mathematics. Computer Tools in Education. 2019. No. 2. Pp. 65-71; DOI: 10.32603/2071-2340-2019-2-65-71

[18] Singh R, Gulwani S, Rajamani S. Automatically Generating Algebra Problems. // Proceedings of the Twenty-Sixth AAAI Conference on Artificial Intelligence. (July 22-26, 2012, Toronto, Ontario, Canada). AAAI Press. 2012. P. 1620-1636.

[19] Abe K., Cortez R., Vazhenin A. Task management strategies for automatic task generation and verification. // Awareness Science and Technology and Ubi-Media Computing (CAST-UMEDIA). 2013 International Joint Conference (2-4 Nov. 2013). IEEE. 2013. P. 601 - 606. DOI: $10.1109 / \mathrm{ICAwST} .2013 .6765510$

[20] Jörg Vollrath. An open access minimum automatic task generation live feedback system for electrical engineering. // 2015 IEEE Global Engineering Education Conference (EDUCON 2015). (18-20 March 2015, Tallinn University of Technology, Tallinn, Estonia). IEEE. 2015. P. 494 - 498. DOI: 10.1109/EDUCON.2015.7096015.

[21] Minh Luan Nguyen, Siu Cheung Hui, Alvis C. M. Fong. Web-Based Mathematics Testing with Automatic Assessment. 12th Pacific Rim International Conference on Artificial Intelligence, Kuching, Malaysia, September 3-7, 2012. Proceedings. PRICAI 2012: Trends Science and education. Bauman Moscow state technical University 295 in Artificial Intelligence, series Lecture Notes in Computer Science. Springer-Verlag Berlin Heidelberg. Vol. 7458. P. 347-358. DOI: 10.1007/978-3642-32695-0_32

[22] Finogenov A. A., Generator of tasks in higher mathematics [Electronic resource]. Access mode: 
http://generatorzadach.ru/ (accessed 8.12.19)

[23] Sepetov D. P., Generator of tasks in physics [Electronic resource]. Access mode: http://kafedra.sepetov.ru/ (accessed 8.12.19)

[24] Posov I. A., Review of generators and methods of generating training tasks / / Educational Technologies and Society. 2014. Vol. 17, No. 4. Pp. 593-609.

[25] Resolution of the Constitutional Court of the Russian Federation of October 8, 2019 N 31-P "On the constitutionality check of the provisions of paragraphs 1 and 2 of article 3 of the Law of the Russian Federation "On employment in the Russian Federation" in connection with the complaint of a citizen $\mathrm{M}$. V. Tchaikovsky"

[26] Balatsky E. V. In search for academic rent // Capital of the Country (Federal Internet edition) [Electronic resource]. - Access mode: http://kapitalrus.ru/articles/article/v_poiskah_akademicheskoj_renty/ (accessed 8.12.19)

[27] Watson, E. (2020). \#Education: The Potential Impact of Social Media and Hashtag Ideology on the Classroom. Research in Social Sciences and Technology, 5(2), 40-56. https://doi.org/10.46303/ressat.05.02.3

[28] Gapsalamov, A. R., Merzon, E. E., Kuznetsov, M. S., Vasilev, V. L., \& Bochkareva, T. N. (2020). The education system in the context of socio-economic transformations. [O sistema educacional no contexto das transformações socioeconômicas] Periodico Tche Quimica, 17(34), 874-883.

[29] Saenko, N., Voronkova, O., Zatsarinnaya, E., \& Mikhailova, M. (2020). Philosophical and cultural foundations of the concept of "nihitogenesis". Journal of Social Studies Education Research, 11(1), 88-103.

[30] Hasan, M., Hatidja, S., Nurjanna, Guampe, F. A., Gempita, \& Ma'ruf, M. I. (2019). Entrepreneurship learning, positive psychological capital and entrepreneur competence of students: A research study. Entrepreneurship and Sustainability Issues, 7(1), 425437. https://doi:10.9770/jesi.2019.7.1(30)

[31] Saenko, N., Voronkova, O., Volk, M., \& Voroshilova, O. (2019). The social responsibility of a scientist: Philosophical aspect of contemporary discussions. Journal of Social Studies Education Research, 10(3), 332345.

[32] Yemelyanov, V. A., Yemelyanova, N. Y., Shved, E. V., Nedelkin, A. A., \& Fatkulin, A. R. (2020). Modeling of the multilayer perceptrons for image recognition of the steel microstructures. Paper presented at the Proceedings of the 2020 IEEE Conference of Russian Young Researchers in Electrical and Electronic Engineering, EIConRus 2020, 952-955. https://doi:10.1109/EIConRus49466.2020.9038971

[33] Plaskova, N. S., Prodanova, N. A., Dikikh, V. A.,
Kerimov, V. E., Kurochkina, I. P., \& Prokofieva, E. V. (2020). Principles of forming a modern accounting and analytical model of commercial organization in digital economy. International Journal of Economics and Business Administration, 8(1), 203-214. https://doi:10.35808/ijeba/419

[34] Borodina, T., Sibgatullina, A., \& Gizatullina, A. (2019). Developing creative thinking in future teachers as a topical issue of higher education. Journal of Social Studies Education Research, 10(4), 226-245.

[35] Polat, S. (2020). Multidimensional Analysis of the Teaching Process of the Critical Thinking Skills. Research in Social Sciences and Technology, 5(2), 134-157. https://doi.org/10.46303/ressat.05.02.8

[36] Poltarykhin, A., Chernukhina, G., Udovik, E., Sukhina, N., Varlamova, V., \& Zavyalov, M. (2020). Economic aspects of the development of human capital in the ecosystem. International Journal of Advanced Science and Technology, 29(9 Special Issue), 2261-2267. 